\title{
The academic base for general practice: the case for change
}

\author{
Justin Allen, Andrew Wilson, Robin Fraser, Denis Pereira Gray
}

\begin{abstract}
University departments of general practice and the postgraduate education system for general practice have developed separately over the past 30 years. This separation is now impeding the academic development of the discipline and causes difficulties with recruitment and career progression. These problems could be eased by the creation of integrated departments. This would establish a critical mass for research and educational development, allow human and other resources to be used more flexibly and effectively, and provide a strong base for undergraduate education, vocational training, higher professional training, and continuing education. It could encourage collaborative ventures with other disciplines and also lead to higher standards of patient care.
\end{abstract}

Education in general practice has made great advances over the past 30 years. The establishment of vocational training has led to the formation of a group of experienced teachers with skills in the teaching of trainees and trainers. Over roughly the same time, but almost entirely separately, university departments of general practice have also been developed. Their main priorities have been to support the increasing contribution of general practice to the undergraduate curriculum and to promote and conduct research in general practice. This division of academic general practice has been acknowledged as harmful to the discipline and has led the Royal College of General Practitioners to state that the long term trend should be towards unity. ${ }^{1}$ Apart from some notable individual achievements, however, progress towards integration has been slow and structural barriers remain. In this paper we examine in detail the effects of separation, propose an integrated alternative that is applicable nationally, and consider how this might be implemented.

In this article the term university departments of general practice includes departments with responsibilities for undergraduate teaching (undergraduate departments) and departments in postgraduate medical schools (postgraduate departments). The term postgraduate general practice includes the regional adviser service, which consists of vocational training and continuing medical education.

\section{The status quo}

UNIVERSITY DEPARTMENTS OF GENERAL PRACTICE

Academic general practice is now established in every undergraduate medical school in the United Kingdom, ${ }^{2}$ and all but three medical schools have established a chair of general practice or its equivalent. Nevertheless, departments vary substantially in size and structure. Some are based on NHS practices; in others clinical academic staff have links with local practices. $^{3}$ Only a few departments include nonclinical academic posts. Many departments have extended their activities beyond the central tasks of undergraduate teaching and research. These include participating in continuing medical education and audit initiatives and providing teaching for diploma courses and masters degrees. Many departments also support health service activities in audit and research for regions, districts, and family health services authorities.

Undergraduate departments of general practice have no responsibility for providing vocational training or continuing medical education. Most doctors therefore lose contact with departments of general practice soon after graduation.

Postgraduate departments of general practice have been established in three universities without a medical school and include two professors. Although their remit in research is identical with that of other university departments, their postgraduate teaching activities have led to closer links with the adviser network than exist in most undergraduate departments.

\section{POSTGRADUATE GENERAL PRACTICE}

Academic medicine in many specialties has been strongly helped by the existence of postgraduate institutes such as the Institutes of Child Health and Psychiatry, etc. These institutes have undertaken considerable research and development in their subject and there are over 100 professors in the British Postgraduate Medical Federation. There are, however, no postgraduate institutes in general practice.

Vocational training for general practice was established in the $1970 \mathrm{~s}^{4}$ and expanded rapidly, so that by the time mandatory training was introduced in $1981^{5}$ a postgraduate education establishment had been developed. The teaching was practice based, and payment for the trainers was derived from a general medical services pool. Schemes were based on the postgraduate centres of local district general hospitals. Half day and day release education programmes were established, their content being arranged by a course organiser, originally often nominated or elected by the trainers. There was little formal training for the task, and payment was as a trainer.

With the appointment of regional advisers a university link was established in $1972,{ }^{\circ}$ but these advisers are accountable to regional postgraduate deans and have not related directly to university departments of general practice. In 1991 the Committee of Regional Advisers in General Practice in England recommended "The Regional Adviser's major responsibilities will continue to be as an academic in general practice" and "The academic support needed for those [advisers] in post should be addressed as a matter of highest priority." Such academic support is not, however, being provided. Indeed, the new general practitioner contract and the requirements of the postgraduate education allowance system have placed a new and substantial responsibility on advisers, who are now required to monitor and develop the provision of education. This increase in educational activity, however, shows the pressing need to include measures of outcome into research on and evaluation of teaching methods and assessment. 
The standard of teaching in vocational training has steadily improved and has come to be widely regarded as the "ideal" to which other disciplines aspire. General practice is the only branch of medicine in which teachers have to meet regionally agreed educational criteria and undertake courses in teaching methods before being allowed to teach. Even the most senior teachers, the regional advisers, are often on time limited contracts and are visited at work as part of a review by external colleagues. Course organisers have developed their teaching skills in a wide variety of one to one and small group methods and in teaching both trainers and trainees. Trainers now have to undergo a rigorous process of training as teachers and of preparing their practices. ${ }^{8}$ The use of video recording has been widely developed and is now an established way of reviewing the performance of the teachers.

This development of teaching skill in postgraduate general practice has not been accompanied by comparable levels of achievement in research, although there have been a few notable individual exceptions. Although some associate advisers have appointments in undergraduate departments, joint appointments are virtually unknown at lecturer/course organiser level. This lack of contact relates to simple factors such as geography and reflects the differing origins and ethos of the groups concerned.

Many postgraduate teachers are finding increasing difficulty in developing and evaluating new ideas-for example, on teaching methods or in assessment -because of a lack of "protected academic time." In the recent survey of the tasks performed by course organisers time for research or professional development was not even mentioned. ${ }^{9}$ An academic base could provide both the stimulus and support for much needed research into postgraduate education.

\section{Problems for general practice caused by separation} RESEARCH: LACK OF OUTPUT AND INFLUENCE

University departments of general practice tend to be small compared with other clinical departments, and may lack critical mass. ${ }^{23}$ Compared with other medical disciplines, the amount and influence of research in general practice is quite small. Good research-and teaching - requires a group of enthusiastic colleagues who can challenge and sustain each other and attract resources. General practice provides unique opportunities for research but much of this research is done by those outside the discipline. Only about $2 \%$ of doctor of medicine degrees from British universities are awarded to general practitioners. ${ }^{10}$ Several departments of general practice feel vulnerable under the new system by which resources are more explicitly directed according to selective indicators of research activity. A vicious cycle is set up in which small departments such as general practice are unable to expand because they lack the critical mass to achieve the required output. This lack of a research culture in general practice impedes the implementation of research findings and reduces the potential of collaborative ventures with other disciplines.

\section{ACADEMIC CREDIBILITY IN POSTGRADUATE GENERAL} PRACTICE

Although highly skilled as teachers, few course organisers or advisers are able to be active in research or to attain the higher degrees and record of research publications needed to be appointed to academic posts, particularly senior posts (again there are several notable exceptions). Protected time for personal development and research is rarely included in the contracts of those in postgraduate education, particularly for associate advisers and course organisers, and the workload of the health service acts as an impedi- ment to such activities. Thus a cycle is established in which higher research degrees are simply not attainable on a wide scale in postgraduate academic general practice. As achievement in research is the most highly regarded criterion by university appointment committees, many able postgraduate teachers with fine records in teaching and scholarship are severely disadvantaged if they wish to pursue a university career.

\section{DIFFICULTIES IN RECRUITMENT}

Difficulty in recruitment is being experienced for posts in postgraduate general practice and in some university departments. Only a few general practitioners have the motivation and skills to participate in teaching and research. Recruits for university departments and for postgraduate general practice are sought from this small pool. Those interested need to decide which wing of academic practice to enter and to accept that there are few opportunities to change over, particularly from postgraduate general practice to university departments.

\section{CONTRIBUTION TO ACADEMIC MEDICINE}

Although general practice is the largest discipline in the medical profession, its influence in most medical schools is small. It has produced no postgraduate deans and only two university deans and one director of a postgraduate medical school. Thus most of the people who can determine the direction and overall content of the education programme for doctors, most of whom will become general practitioners, are drawn from hospital based specialties.

\section{OVERLAPPING ROLES IN EDUCATION AND TRANNING}

Teaching in general practice has become the most professionalised of any other medical discipline. Most departments have a programme of staff development in teaching techniques, particularly small group work, role play, and video analysis ${ }^{2}$; the same type of programmes are organised for course organisers by regional advisers. Postgraduate and undergraduate teachers rarely share skills and experience, however, which is clearly wasteful.

Recent developments in postgraduate education threaten to cause more problems. Higher professional training, often leading to higher degrees or diplomas, is currently being developed in many general practice university departments, but it is specifically aimed at those who have completed vocational training. Currently, the length of vocational training is under review by the Royal College of General Practitioners, whose policy remains that vocational training for general practice should last five years. There is a potential for confusion and duplication of roles between university departments and postgraduate providers as this development continues.

\section{An integrated department of general practice}

As a result of a historical separation, an integrated academic university base for general practice education and training has never been properly developed. Although two people have held posts simultaneously as both professor of general practice and regional adviser, and some advisers have held posts in undergraduate departments, these have been fortuitous appointments reflecting personal achievement. They have not, as in countries such as the Netherlands, Australia, New Zealand, and the United States, been a reflection of a formally integrated structure incorporating both undergraduate and postgraduate wings of academic general practice.

The current set up in the United Kingdom creates barriers to collaboration and is hindering the development of both academic wings (fig 1). Duplication arises 


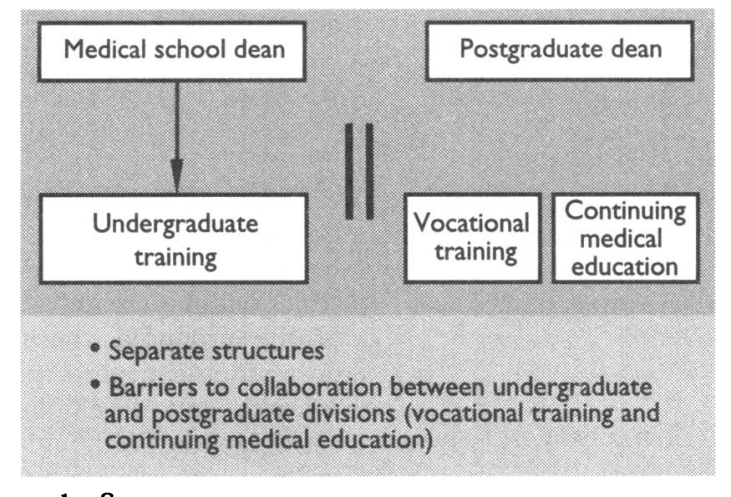

FIG $1-$ Status quo

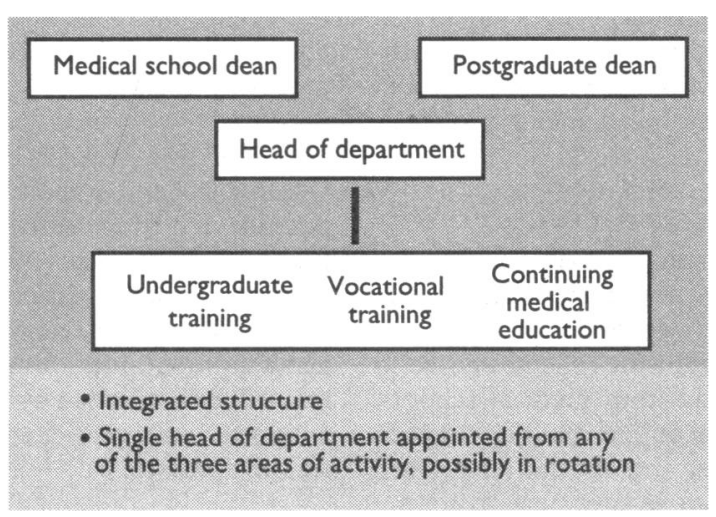

FIG 2-The vision

in some areas and deficiencies in others. It is crucial for the discipline of general practice as a whole that these issues are addressed as a matter of urgency.

THE VISION

In universities with an undergraduate medical school there are strong arguments for establishing integrated departments of general practice, incorporating the current departments, the network of regional and associate advisers, course organisers, and general practice tutors (fig 2). Such a department would also support vocational training in the area for which the university was responsible. It would house several professors, acknowledging specific knowledge of research, audit, and undergraduate and postgraduate education. (The first step towards such an integrated department has already occurred in Glasgow, where the regional adviser has been appointed to a personal chair so that the university now has two professors.) Clinical academics within the department would all have part time commitments to a practice and protected time for research. Areas of individual responsibility would reflect career development and the needs of the department. A head of department would be appointed from either the postgraduate or the undergraduate wing, or possibly in rotation. Individual academics would be accountable to the head of department, who would report to the medical school dean and postgraduate dean as appropriate.

\section{Transitional phases}

The first stage is to encourage functional collaboration between existing departments of general practice and their postgraduate colleagues (fig 3). Many opportunities for such collaboration exist, but because of reasons of history and sometimes geography not all are used to advantage. Relocation of departments so that they are physically close to each other would greatly enhance such informal collaboration.
The next stage is for all aspects of general practice education to take place within a school of general practice with a single administrative structure (fig 4). Undergraduate education, vocational training and continuing medical education would be coordinated by a committee including representatives from all these disciplines and both medical school and postgraduate deans. These transitional phases would not in themselves require any extra funding.

\section{Advantages}

INCREASED ACTTVITY AND INNOVATION IN RESEARCH AND TEACHING

These departments would provide the critical mass for research activity and educational development that is lacking in postgraduate general practice and many existing departments. Skill in subjects of common interest could be pooled to the advantage of undergraduate and postgraduate education. From a strong academic base with skills in research and education the problems of lack of research culture and of mechanisms for audit in practice could be addressed.

\section{BROADENING THE SCOPE OF TEACHERS}

The integration of regional and associate adviser and course organiser posts with existing university departments would clearly highlight research opportunities and expectations. It would encourage many currently working in postgraduate education-particularly junior staff-to acquire and develop skills in research and scholarship. It would also allow those working almost entirely with undergraduate teaching in medical schools to increase their contact with general practice in the health service.

\section{IMPROVED RECRUITMENT AND CAREER STRUCTURE}

The small pool of teaching and research skills could be deployed more flexibly and rationally in integrated schools of general practice. In time interest and recruitment will probably be increased. A more unified

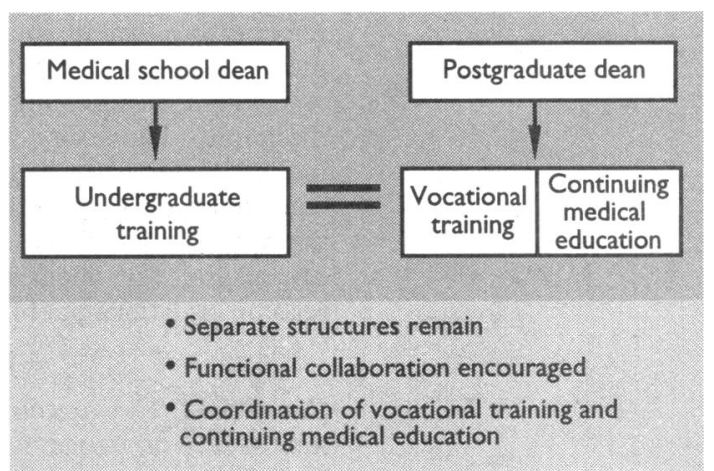

FIG 3-First transitional phase

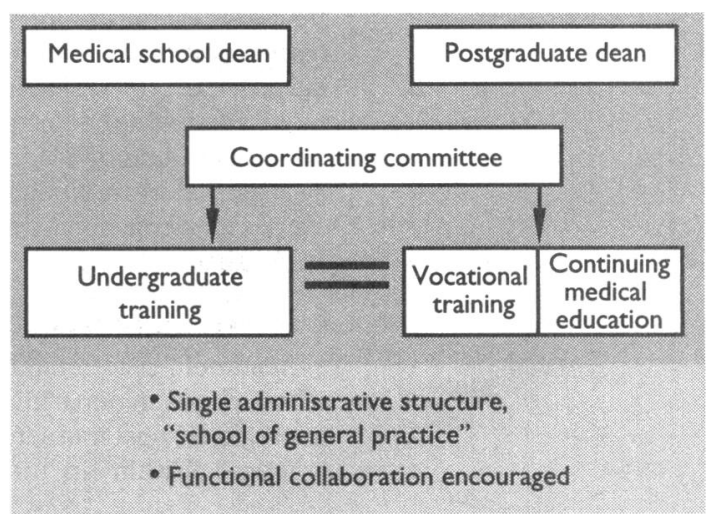

FIG 4-Second transitional phase 
approach would also improve the opportunities for career progression both within and between undergraduate and postgraduate education and research.

SEAMIESS EDUCATION FOR GENERAL PRACTICE

The transition from undergraduate education to vocational training and, for those who want it, higher professional training would be smoother and more easily achieved if departments were integrated.

\section{Disadvantages}

SEPARATION OF TRAINING FOR GENERAL PRACTICE FROM THE REST OF POSTGRADUATE MEDICINE

The creation of integrated departments of general practice could discourage trainees from rethinking career choices between general practice and other specialties. Little such interchange occurs under the present system, however, and we think that if appropriate communications are preserved flexibility could at least be maintained or improved if our proposals were adopted.

\section{PROBLEMS FOR PERIPHERAL TRAINING SCHEMES}

Under our proposal vocational training schemes based in university centres would be part of an integrated department. This would be much more difficult to achieve practically for the schemes based in district general hospitals away from medical schools. Similar problems will be faced by general practice tutors in peripheral hospitals, and special efforts will be required to integrate them in any new structure. Efforts would have to be made to maintain and establish links with such peripheral schemes and to be sensitive to their need for support. More part time academic posts would have to be established away from the university centre to act as local resources.

\section{The Royal College of General Practitioners}

The Royal College of General Practitioners has had a crucial role in the development of both undergraduate and postgraduate education for general practice. Its membership examination is the only national assessment for general practitioners, and the college has a vital role in maintaining educational standards for the discipline. University departments need a strong national college to which the government can turn for consultation on academic matters and which coordinates national policies. The college should have a central role in facilitating the implementation of recommendations put forward in this paper.

\section{Problems to be overcome ACADEMIC ATTITUDES}

To facilitate the process of integration academic titles will need to be granted to many of those currently in the purely provider posts of postgraduate education. Few of these postholders will have higher degrees or a research background for the very reason that they are in provider roles. Nevertheless, universities will be required to adopt a flexible and discretionary approach to the awarding of academic titles; this process should be regarded as traditional. Similar discretion had to be exercised when departments of general practice were established.

\section{CURRENT LINES OF ACCOUNTABILTTY}

Academic accountability is currently to the medical school deans in departments of general practice, and to the regional postgraduate dean in postgraduate general practice. Within an integrated department account- ability would be to both deans. Although this seems to be administratively clumsy, the aspects of work for which each is responsible could be easily defined.

FUNDING

Unlike in many other structural changes, all the postholders are currently in post and funded, albeit from different sources. As integration proceeds the pay scales will require harmonisation. One of the purposes of the proposed change is to allow many in the postgraduate general practice time to take part in research and development. This will require some extra support. Although the early transitional phases will not require extra funding, this does not imply that academic general practice is currently properly funded. Indeed, the reverse is true, and it is crucial for the discipline of general practice that the balance is redressed. There are 0.45 academic posts per consultant in the hospital service but only one per 165 general practice principals. ${ }^{1}$

\section{VIEW OF MAINSTREAM GENERAL PRACTICE}

Some general practitioners view academic general practice as a fringe activity carried out in ivory towers. Some may be even more suspicious of a stronger academic base, especially in vocational training. Contact between any new integrated department and general practitioners must be maintained or enhanced; this will be facilitated by the greater contact of teachers with the enlarged single network of teaching and training practices.

\section{Conclusion}

We have considered the consequences for the comparatively new academic specialty of general practice of having separate undergraduate and postgraduate structures and functions. Existing barriers must be broken down quickly as a first phase to integration. The Association of University Departments of General Practice, the United Kingdom Conference of Regional Advisers, and the Committee of Regional Advisers in General Practice in England should facilitate this process; the Royal College of General Practitioners also has an important part to play. Several departments and schemes have started working in closer collaboration, and discussions are taking place nationally between the concerned bodies. The next stages of practical implementation can then be developed according to local circumstances and experience.

1 Royal College of General Practitioners. A college plan. Priorities for the furure. London: RCGP, 1990. (Occasional paper 49.)

2 Fraser RC, Preston-Whyte ME. The contribution of academic general practice to undergraduate medical education. London: RCGP, 1988. (Occasional pape 42.)

3 Howie JGR, Hannay DR, Stevenson JSK. The Mackenzie report. General Practice in the medical schools of the United Kingdom, 1986. Edinburgh: Mackenzie Fund, 1986.

4 Pereira Gray DJP. The history of vocational training. In: Training for general practice. Plymouth: Macdonald and Evans, 1981.

5 National Health Service of England and Wales. The National Health Service (vocational training) regulations 1979. London: Department of Health and Social Security, 1979. (Staturory instrument No 1644)

6 Department of Health and Social Security and the Welsh Office. Appointment of regional advisers in general practice. London: DHSS, 1972. (Circular HM (72) 75 .

7 Committee of Regional Advisers in General Practice. The remit and responsibilities of regional advisers in general practice in England. Report of CRAGPIE working party. London: CRAGPIE, 1991.

8 Joint Committee on Postgraduate Training for General Practice. Recommenda tions to regions for the establishment of criteria for the approval and reapproval of trainers in general practice. London: JCPTGP, 1985.

9 General Medical Services Committee and Department of Health. Course organisers workload survey 1991. London: Department of Health, 1991.

10 Williams WO. A survey of doctorates by thesis among general practitioners in the British Isles from 1973 to 1988. Br f Gen Pract 1991;40:491-4.

11 Pereira Gray D. Research in general practice: law of inverse opportunity. $B M \mathcal{J}$ 1991;302:1380-2.

(Accepted 22 fuly 1993) 